\title{
Implications of potential future grand solar minimum for ozone layer and climate
}

\author{
Pavle Arsenovic $^{1}$, Eugene Rozanov ${ }^{1,2}$, Julien Anet $^{3}$, Andrea Stenke ${ }^{1}$, Werner Schmutz ${ }^{2}$, and Thomas Peter ${ }^{1}$ \\ ${ }^{1}$ Institute for Atmospheric and Climate Science, ETH, Zürich, Switzerland \\ ${ }^{2}$ Physikalisch-Meteorologisches Observatorium Davos/World Radiation Center, Davos, Switzerland \\ ${ }^{3}$ Zürich University of Applied Sciences, Winterthur, Switzerland
}

Correspondence: Pavle Arsenovic (pavle.arsenovic@env.ethz.ch)

Received: 31 August 2017 - Discussion started: 4 October 2017

Revised: 10 January 2018 - Accepted: 30 January 2018 - Published: 8 March 2018

\begin{abstract}
Continued anthropogenic greenhouse gas (GHG) emissions are expected to cause further global warming throughout the 21 st century. Understanding the role of natural forcings and their influence on global warming is thus of great interest. Here we investigate the impact of a recently proposed 21 st century grand solar minimum on atmospheric chemistry and climate using the SOCOL3-MPIOM chemistry-climate model with an interactive ocean element. We examine five model simulations for the period 20002199 , following the greenhouse gas concentration scenario RCP4.5 and a range of different solar forcings. The reference simulation is forced by perpetual repetition of solar cycle 23 until the year 2199. This reference is compared with grand solar minimum simulations, assuming a strong decline in solar activity of 3.5 and $6.5 \mathrm{~W} \mathrm{~m}^{-2}$, respectively, that last either until 2199 or recover in the 22nd century. Decreased solar activity by $6.5 \mathrm{~W} \mathrm{~m}^{-2}$ is found to yield up to a doubling of the GHG-induced stratospheric and mesospheric cooling. Under the grand solar minimum scenario, tropospheric temperatures are also projected to decrease compared to the reference. On the global scale a reduced solar forcing compensates for at most $15 \%$ of the expected greenhouse warming at the end of the 21 st and around $25 \%$ at the end of the $22 \mathrm{nd}$ century. The regional effects are predicted to be significant, in particular in northern high-latitude winter. In the stratosphere, the reduction of around $15 \%$ of incoming ultraviolet radiation leads to a decrease in ozone production by up to $8 \%$, which overcompensates for the anticipated ozone increase due to reduced stratospheric temperatures and an acceleration of the Brewer-Dobson circulation. This, in turn, leads to a delay in total ozone column recovery from an-
\end{abstract}

thropogenic halogen-induced depletion, with a global ozone recovery to the pre-ozone hole values happening only upon completion of the grand solar minimum.

\section{Introduction}

Global warming is one of the main societal problems. The observed global warming since the pre-industrial period (1850-1900) until the end of the 20th century (1986-2005) is estimated to be around $0.6^{\circ} \mathrm{C}$ (IPCC, 2013). The global mean surface temperature is expected to continue to rise in the 21 st century due to human activity and an associated increase in atmospheric greenhouse gas (GHG) concentrations. In its fifth assessment report (AR5), the Intergovernmental Panel on Climate Change (IPCC) examined four Representative Concentration Pathways (RCPs) of GHG concentration trajectories (IPCC, 2013). The projected warming (2081-2100 mean minus 1986-2005 mean) is $1 \pm 0.4{ }^{\circ} \mathrm{C}$ for RCP2.6, $1.8 \pm 0.5^{\circ} \mathrm{C}$ for $\mathrm{RCP} 4.5,2.2 \pm 0.5^{\circ} \mathrm{C}$ for RCP6.0 and $3.7 \pm 0.7^{\circ} \mathrm{C}$ for RCP8.5, given as multimodel mean \pm standard deviation of the various IPCC models. In December 2015, many countries agreed to make an effort to reduce their emissions of GHG into the atmosphere in order to keep the global surface temperature rise below $2{ }^{\circ} \mathrm{C}$ above pre-industrial levels. This agreement was adopted under the United Nations Framework Convention on Climate Change (UNFCCC), and it is now known as the Paris climate agreement. RCP2.6 is the only GHG concentration scenario that limits the global mean surface temperature increase at $2{ }^{\circ} \mathrm{C}$ at the end of the 21 st century (van Vuuren et al., 2011b). 
A second major anthropogenic influence on the atmosphere results from the release of ozone-depleting substances (ODSs). Molina and Rowland (1974) warned against humanproduced chemicals which play an important role in stratospheric ozone depletion, leading to a thinning of the ozone layer, thereby increasing the incidents of skin cancer and eye cataracts, but also affecting plants, crops and the oceanic ecosystem (e.g. Hegglin et al., 2015). Observations confirmed the decline in global ozone concentrations and revealed that the maximum ozone depletion occurred in the springtime Antarctic stratosphere, a phenomenon commonly known as the "ozone hole". As a response to ozone depletion, the Montreal Protocol was established in 1987, which prohibited production of certain ODSs and their subsequent release into the atmosphere. In their latest report on the ozone layer, the World Meteorological Organization (WMO) and United Nations Environmental Programme (UNEP) projected that the reduction of ODSs will lead to an ozone increase in the 21st century, reaching pre-1980 levels in the second half of the century, with detailed recovery times depending on latitude (WMO, 2014).

The projections of Earth's climate by the IPCC and of the ozone layer by WMO and UNEP assume solar irradiance to remain constant with respect to both incoming integrated power (total solar irradiance, TSI) and spectral distribution of the power (spectral solar irradiance, SSI). However, the Sun is a variable star and its output varies over vast timescales. Apart from an 11-year solar cycle, the solar activity oscillates in the cycles of the order of hundreds of years, called "grand solar minima" and "grand solar maxima". Several recent publications suggest a new grand solar minimum will occur in the 21st century (Abreu et al., 2010; Lockwood et al., 2011; Roth and Joos, 2013) and will last even until the end of the 22nd century (Steinhilber and Beer, 2013). Such events might have a significant impact on climate and on the ozone layer. As an example, the Dalton minimum (1790-1830) is thought to have contributed to significant cooling in Europe (Brugnara et al., 2013; Luterbacher et al., 2004). It was characterized by reduced solar irradiation (Hoyt and Schatten, 1998 ), estimated to range between a moderate $\sim 1 \mathrm{~W} \mathrm{~m}^{-2}$ (Kopp, 2016) and as much as $\sim 5 \mathrm{~W} \mathrm{~m}^{-2}$ (Shapiro et al., 2011) below present values. Anet et al. (2014) applied the forcing derived by Shapiro et al. (2011) to modulate the solar input in a climate model and found that, among other natural factors (e.g. volcanic activity), the simulated cooling was to a large degree caused by low solar activity. A grand solar minimum which was even more prolonged than the Dalton Minimum was the Maunder Minimum, the period between approximately 1645 and 1715 when sunspots were exceedingly rare.

Energetic particle precipitation (EPP) is closely related to solar activity. Energetic particles have the ability to produce odd nitrogen and odd hydrogen species, $\mathrm{NO}_{x}([\mathrm{~N}]+[\mathrm{NO}]+$ $\left.\left[\mathrm{NO}_{2}\right]\right)$ and $\mathrm{HO}_{x}\left([\mathrm{H}]+[\mathrm{OH}]+\left[\mathrm{HO}_{2}\right]\right)$, which are known to catalytically deplete ozone. Amongst all energetic particles, galactic cosmic rays (GCRs) are the most energetic $(1 \mathrm{MeV}$ to $5 \times 10^{13} \mathrm{MeV}$; Dorman, 2004), so that they penetrate deep into the atmosphere. Their influence is largest in the polar lower stratosphere and upper troposphere (Calisto et al., 2011; Jackman et al., 2016; Mironova et al., 2015). Their intensity is anticorrelated with the solar activity (Bazilevskaya et al., 2008). Conversely, low energy electrons (LEEs) are stopped already in the upper atmosphere and produce $\mathrm{NO}_{x}$ in the thermosphere, above $80 \mathrm{~km}$ altitude. During polar night, $\mathrm{NO}_{x}$ created by LEEs is then transported downwards and affects mesospheric and stratospheric ozone (Rozanov et al., 2012). Therefore, inclusion of these processes in chemistryclimate models is important for a realistic representation of ozone variability.

Reductions in solar activity may lead to a partial compensation of the radiative forcing stemming from increased anthropogenic emissions of GHGs. A number of studies were conducted to assess if a potential future grand solar minimum would lead to a possible reduction in the projected global warming. Mokhov et al. (2008) performed 21st century simulations with different solar, volcanic and anthropogenic forcings. Their analysis of the response of global mean nearsurface temperature to various solar scenarios showed that solar activity variations of up to $2 \mathrm{~W} \mathrm{~m}^{-2}$ impose only small changes in the surface temperature. Meehl et al. (2013) used the climate model CESM1 WACCM to investigate whether a future Maunder-like minimum could stop global warming. They found that such a potential grand solar minimum with TSI drop of about $3.9 \mathrm{~W} \mathrm{~m}^{-2}(0.25 \%)$ from 2024 to 2065 would slow down and delay anthropogenic global warming, such that surface temperatures would be lower than the reference by several tenths of a degree by the end of the grand minimum. However, their study focused on surface temperature, whereas chemical effects and stratospheric changes caused by a grand solar minimum were not investigated. A follow-up study using the same model but a more conservative solar minimum found important regional effects in the northern high latitudes, suggesting a reduction of the Arctic amplification (Chiodo et al., 2016). Another modelling study was performed by Anet et al. (2013) using the SOCOL3MPIOM model. Their work also showed a reduction of surface temperatures of the same order of magnitude as shown by Meehl et al. (2013) and Chiodo et al. (2016) and a delay of the ozone recovery back to the "pre-ozone hole" conditions. Ineson et al. (2015) used the HadGEM2-CC climate model to evaluate possible impacts of a grand solar minimum on climate. They found that a reduction of solar irradiance of about $1.75 \mathrm{~W} \mathrm{~m}^{-2}(0.13 \%)$ would decrease global mean temperature by approximately $0.1 \mathrm{~K}$ for the second half of the 21st century. Maycock et al. (2015) used the same model and applied a decrease in TSI and UV over the second half of the 21 st century of $0.12 \%\left(1.63 \mathrm{~W} \mathrm{~m}^{-2}\right)$ and $0.85 \%$ respectively, compared to present values. They found that the decrease in solar activity would reduce global annual nearsurface temperature by around $0.1 \mathrm{~K}$ and cool the stratopause 
region by around $1.2 \mathrm{~K}$. However, their climate model lacked interactive chemistry, and hence change in ozone and the influence of the EPP were neglected.

The present work is a continuation and extension of the study of Anet et al. (2013). The novel aspect with respect to Anet et al. (2013) is that the minimum is extended in time and the full extent of the response over the 21 st and 22 nd century is analysed.

\section{Methods}

We use the coupled chemistry-climate model SOCOL3MPIOM (Stenke et al., 2013; Muthers et al., 2014), which consists of the atmospheric model coupled to the chemistry module and the ocean model. The atmospheric component is a general circulation model ECHAM5.4, a spectral model based on primitive equations with temperature, vorticity, divergence, surface pressure, humidity and cloud water as prognostic variables (Manzini et al., 2006; Roeckner, 2003; Roeckner et al., 2006). Here it was applied in a configuration with T31 spectral horizontal truncation (approximately $3.75^{\circ} \times 3.75^{\circ}$ horizontal resolution) and 39 vertical levels from the ground to $0.01 \mathrm{hPa}(\sim 80 \mathrm{~km})$. The chemistry module is MEZON (Egorova et al., 2003; Rozanov et al., 1999), which computes the tendencies of 41 gas species, taking into account 200 gas-phase, 16 heterogeneous and 35 photolytical reactions. The oceanic component is MPIOM, a primitive equation model which includes a dynamic/thermodynamic sea-ice module and uses a curvilinear orthogonal grid which allows for various setups. In our study it was used with a nominal horizontal resolution of $3^{\circ}$, divided vertically into 40 levels from the ocean surface to the bottom (for more details see Muthers et al., 2014).

We simulated five different scenarios, each with two ensemble members, with the only difference between these experiments being the imposed solar forcing: four experiments with grand solar minima of two different strengths and two different durations, plus a reference simulation (see Fig. 1). The reference simulation (hereafter termed REF) is forced by a perpetual repetition of solar cycle 23 until the year 2199 . Two experiments assume a relatively weak drop (termed WD or WDR) in the solar forcing with TSI approximately $3.5 \mathrm{~W} \mathrm{~m}^{-2}$ lower than in REF ( $0.26 \%$ reduction). The assumed solar minimum either continues throughout the 22nd century (WD) or starts to recover (WDR) soon after reaching the minimum of $-3.5 \mathrm{~W} \mathrm{~m}^{-2}$ around the year 2087. Two further experiments assume a strong drop (termed SD or SDR) with TSI about $6.5 \mathrm{~W} \mathrm{~m}^{-2}$ lower $(0.48 \%$ reduction) than in REF, again either continuing throughout the 22nd century (SD) or recovering (SDR) soon after reaching the minimum (Fig. 1). Since this is a continuation of the study of Anet et al. (2013), we are using the same solar forcing as they did. It is calculated using the method developed by Shapiro et al. (2011) based on the solar modulation potential $(\Phi)$. The drop in the part of the UV spectrum that is most important for ozone production $(180-250 \mathrm{~nm})$ is about $9 \%$ in WD and WDR and about $15 \%$ in SD and SDR. The complete description of applied spectral solar irradiance (SSI) can be found in Anet et al. (2013, Fig. S3). The prolonged grand solar minimum scenarios (WD and SD) are based on the same $\Phi$ : WD represents the upper envelope of the uncertainty range of the solar forcing reconstruction, while SD represents the mean of solar forcing. The same applies to WDR and SDR, but the $\Phi$ follows the recovery of grand solar minimum. We call the scenarios "weak" and "strong" for clear distinction, though it must be noted that both scenarios actually represent stronger irradiance reductions than those generally assumed in previous studies (Chiodo et al., 2016; Ineson et al., 2015; IPCC, 2013; Maycock et al., 2015; Meehl et al., 2013; Mokhov et al., 2008). Previous estimates regarding the TSI decrease during the Maunder Minimum compared to present-day values range from somewhere close to present 11-year solar minima (Schrijver et al., 2011), to reductions of 0.15 to $0.3 \%$ below present solar minima (Foukal et al., 2011) all the way to more than $0.4 \%$ below present solar minima derived by Shapiro et al. (2011) and applied here in the SD and SDR scenarios. The stronger reductions in TSI have been criticized as being too large (Feulner, 2011), but here we regard these estimates as an absolute lower bound in TSI. Judge et al. (2012) found the Shapiro et al. (2011) estimates to be within the limits set by current stellar data. However, they have likely over-estimated quiet-Sun irradiance variations by about a factor of 2, based upon a re-analysis of sub-millimetre data from the James Clerk Maxwell telescope. This is the basis for the WD and WDR scenarios employed here. As in Meehl et al. (2013) we emphasize that the caveat for the present study is that a hypothetical future Maunder Minimum-type event could feature a smaller reduction of TSI and an even lower climate system response. We therefore want to stress that the results from our study represent the uppermost possible global climate reactions to a very strong solar forcing reduction.

To extend the simulations to the 22nd century, we repeated the last solar cycle for WD and SD simulated by Anet et al. (2013) for the year 2090 (Fig. 1) until the year 2199, as was suggested by Steinhilber and Beer (2013). For WDR and SDR we mirrored SSI values backwards from 2088 into the future. This way we constructed that solar activity recovers to pre-grand solar minimum values in about 2170-2180. The parameterizations of galactic cosmic rays, solar energetic protons and low energy electrons were introduced as in Rozanov et al. (2012). Apart from solar irradiance, $\Phi$ is used to parameterize GCR (based on Usoskin et al., 2010) and also to develop the geomagnetic activity $\left(A_{p}\right)$ index needed for the LEE parameterization. As mentioned above, since "weak" and "strong" scenarios are developed from the same $\Phi$, the EPP forcing is identical in WD and SD to in WDR and SDR scenarios.

Tropospheric aerosols are adapted from NCAR Community Atmospheric Model (CAM3.5) simulations with a bulk 


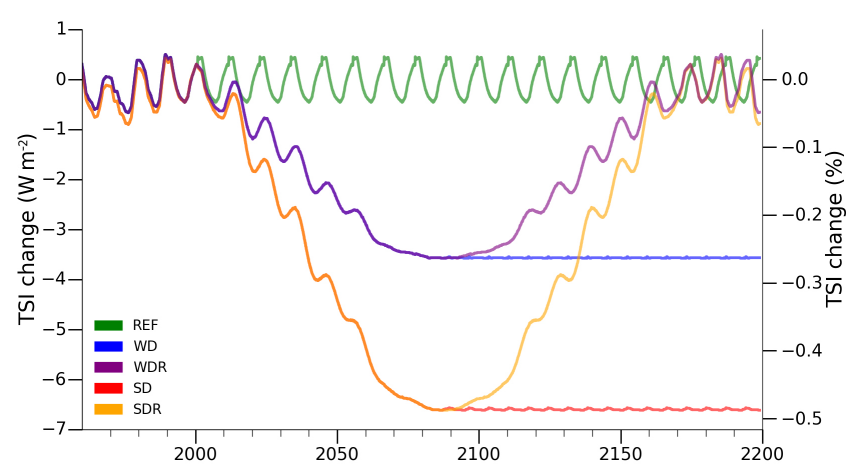

Figure 1. Total solar irradiance change relative to the mean of the REF scenario (green line) in watts per square metre $\left(\mathrm{W} \mathrm{m}^{-2}\right.$; left axis) and percentage (\%; right axis) used in the simulations. Weak drop (WD) in blue, weak drop with recovery (WDR) in purple, strong drop (SD) in red and strong drop with recovery (SDR) in orange.

aerosol model forced with the Community Climate System Model 3 (CCSM3) sea surface temperatures and the 20002100 CMIP5 emissions. For the 22nd century simulations, they are fixed at 2090 levels. Stratospheric aerosols are kept at background levels except for the following four randomly chosen volcanic eruptions in the 21st century: a Fuego-like eruption in 2024, a smaller eruption in 2033, an Agunglike eruption in 2060 and again a smaller eruption in 2073 (Anet et al., 2013, 2014). For the 22nd century we assume four identical small eruptions (with a magnitude between the eruptions in 2033 and 2073) in the years 2115, 2137, 2166 and 2187. The concentrations of GHGs and ODSs follow the CMIP5 RCP4.5 scenario (Meinshausen et al., 2011; van Vuuren et al., 2011a), while the quasi-biennial oscillation (QBO) wind fields are nudged (for more details on the experimental set-up see Anet et al., 2013).

\section{Results}

In order to understand the influence of a future grand solar minimum on climate and ozone layer evolutions, we first investigate the future evolution for the individual solar forcing scenarios. Subsequently we calculate differences in various quantities between the applied solar scenarios and REF for the future (2090-2099) to elucidate the role of the solar forcing in modulating GHG-driven temperature trends.

\subsection{Temperature response}

The global mean surface temperature evolution is displayed in Fig. 2. As shown by Anet et al. (2013), the global mean surface temperature rises in the 21st century in all three scenarios (REF, WD, SD). The difference in global surface temperature between REF and SD, averaged over the last 20 years of the 21 st century, is about $0.3 \mathrm{~K}$ (as also found by

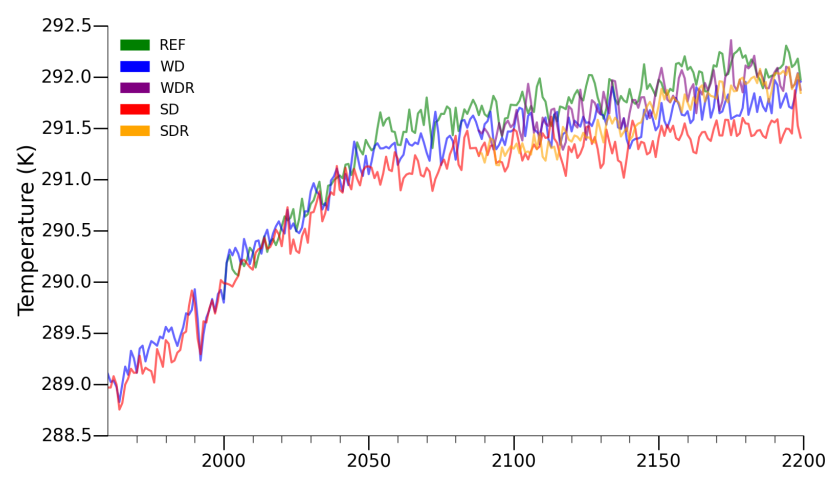

Figure 2. Annual global mean surface temperature in $\mathrm{K}$ of ensemble means from 1960 to 2199 .

Anet et al., 2013). Should the grand solar minimum persist until the end of the 22nd century, the difference between REF and SD would increase to about $0.6 \mathrm{~K}$ (averaged over 21802199 ), which is about $25 \%$ of projected global warming of $2.3 \mathrm{~K}$ at the end of the $22 \mathrm{nd}$ century compared to the base period (1986-2005). The continued temperature increase after 2100 is supported by the thermal inertia of the ocean, as all forcings are kept constant in the 22nd century.

In the case of a recovery from a solar minimum within the 22nd century, the difference of global surface temperature between REF and SDR, averaged over the last 20 years of the $22 \mathrm{nd}$ century, is computed to be only about $0.1 \mathrm{~K}$. This temperature response would compensate for just $\sim 4 \%$ of the anthropogenic temperature increase at the end of the 22nd (2180-2199) century. In other words, an occurrence of the grand solar minimum in the 21st century followed by its recovery would only slightly reduce global surface temperature.

In REF, anthropogenic forcings according to RCP4.5 lead to a warming of the troposphere and a cooling of the stratosphere and mesosphere, as indicated in Fig. 3a. The tropospheric warming reaches a maximum of around $3 \mathrm{~K}$ in the tropical upper troposphere. Tropospheric warming is mainly caused by the surface warming due to an increase in down-welling infrared radiation by GHG, enhanced by latent heat release in the middle troposphere. The temperature decrease in the stratosphere and mesosphere comes from increased cooling rates due to the GHG concentration rise (IPCC, 2013). The secondary maximum in the Antarctic lower stratosphere around $100 \mathrm{hPa}$ is explained by the ozone recovery following the limitation of ODS emissions. Li et al. (2009) used the Goddard Earth Observing System chemistry climate model to evaluate temperature and ozone response to GHG increases and ODS declines. They found a warming of the troposphere in the second half of the 21st century of up to $4 \mathrm{~K}$ compared to the mean 1975-1984 values, accompanied by a cooling of the stratosphere of up to $8 \mathrm{~K}$. Our results for the same period (not shown) agree very well with their study. In the SD scenario the warming of the 

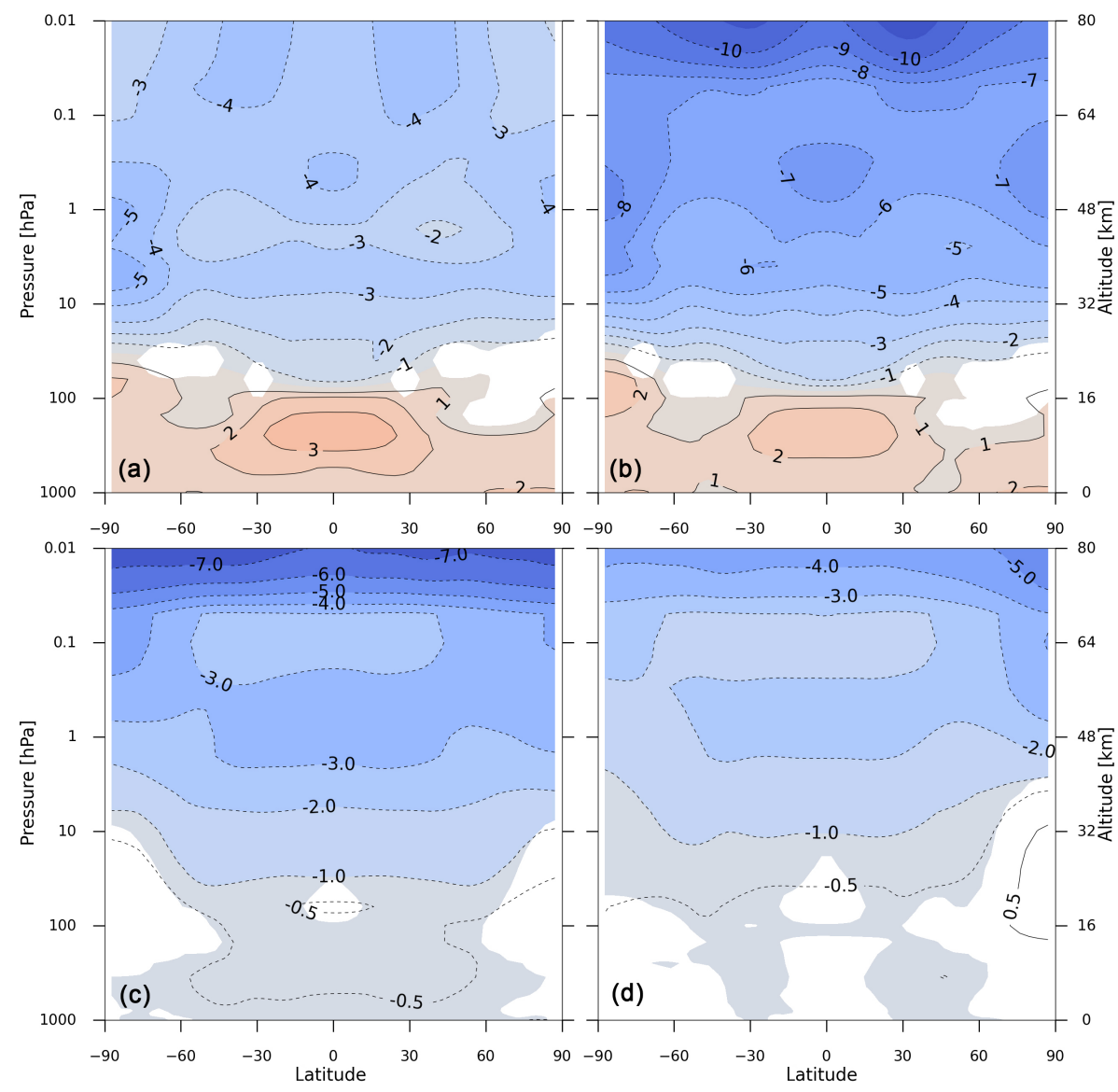

Figure 3. Annual zonal mean temperature difference in K of ensemble means of future (2090-2099) minus near present (2000-2009) for REF (a) and SD (b). The lower two plots show absolute differences of SD minus REF (c) and WD minusREF (d) under future conditions (2090-2099). Coloured regions are significant at the $95 \%$ confidence level (calculated using a Student $t$ test). Colour interval is $1 \mathrm{~K}$.

whole troposphere continues into the 22 nd century relative to the end of the 21 st, with an additional warming peaking at around $1 \mathrm{~K}$ in tropics (not shown), while stratospheric temperatures do not further change during that century. The latter is expected, as the stratosphere has a relatively short thermal relaxation time of less than a month (Newman and Rosenfield, 1997).

Figure $3 \mathrm{~b}$ shows the temperature difference between future and present for the SD scenario. Relative to REF in Fig. 3a, the temperature response pattern shows a reduced warming by up to $1 \mathrm{~K}$ in the troposphere, but a more intensive cooling in the stratosphere and mesosphere. The analysis of the zonal annual mean temperature presented by Maycock et al. (2015) showed the most intense cooling around the stratopause of up to $1.5 \mathrm{~K}$ for the $2050-2099$ period. Our results for the same period suggest a similar temperature pattern (not shown). However, the magnitude is larger: the most pronounced cooling is located above the stratopause and amounts to around $2 \mathrm{~K}$ in the WD and $3 \mathrm{~K}$ in the SD scenario. The difference in magnitude is related to a smaller decrease in the solar UV irradiance in their study.
The impact of SD forcing relative to GHGs is quantified as the difference between SD and REF (Fig. 3c). The temperature difference increases from the tropopause to the mesopause up to $-7 \mathrm{~K}$. Cooling in the troposphere of around $0.5 \mathrm{~K}$ is also found, but this can compensate for less than $20 \%$ of the warming caused by anthropogenic GHG emissions. As expected, due to the lower UV forcing, the WD scenario (Fig. 3d) shows a similar difference pattern, but with a smaller magnitude.

For the RCP4.5 scenario, climate models also predict a warming of about $2 \mathrm{~K}$ at the end of the 21 st century (2081-2100) compared to the 1986-2005 reference period (Fig. 12.8, IPCC, 2013). As the ocean has a larger heat capacity and thermal inertia than the land surface and the atmosphere, the warming over land is more pronounced. The increase is most prominent near the poles of both the Northern Hemisphere (up to $5 \mathrm{~K}$ ) and Southern Hemisphere (up to $3 \mathrm{~K}$ ) (Fig. 12.11, IPCC, 2013), a feature known as polar amplification (Serreze and Barry, 2011). Comparing the end of the 21st century (2090-2099) to its beginning (2000-2009), our model simulates the polar amplification as well: REF yields 

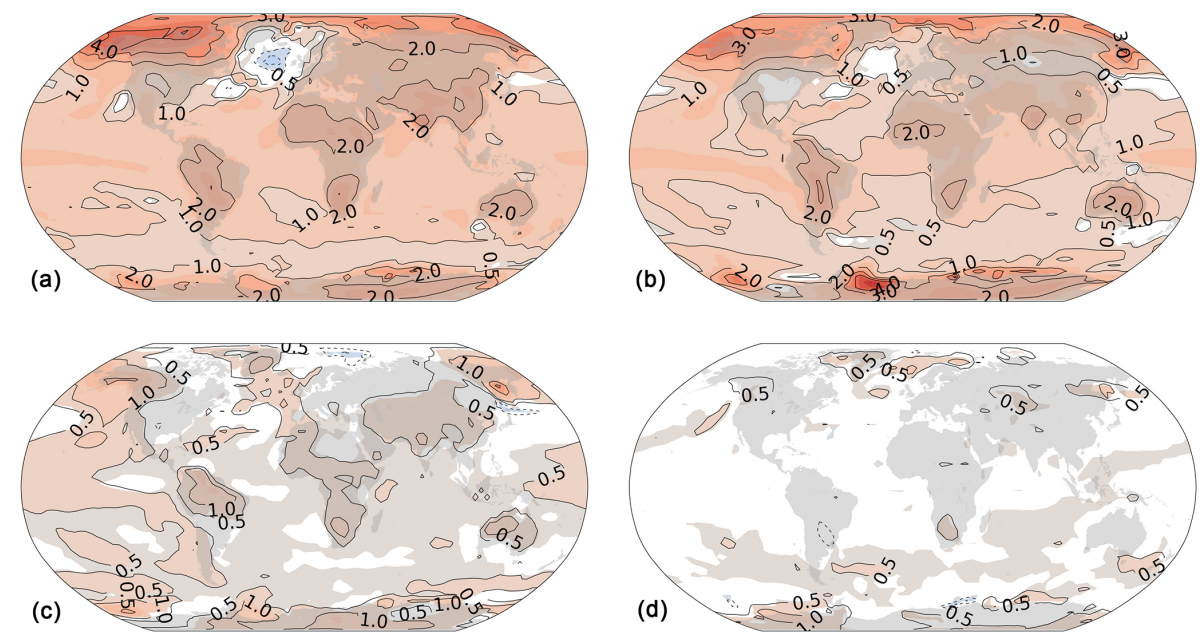

Figure 4. Spatial distribution of surface temperature difference in K of ensemble means of future (2090-2099) minus near present (20002009) for REF (a) and SD (b), and of far future (2190-2199) minus intermediate future (2090-2099) for REF (c) and SD (d). Coloured regions are significant at the $95 \%$ confidence level (calculated using a Student $t$ test). Colour interval is $0.5 \mathrm{~K}$.

an increase of up to $4 \mathrm{~K}$ in North America and of up to $2 \mathrm{~K}$ in Antarctica (Fig. 4a). The other continental regions warm up by around $2 \mathrm{~K}$, while the sea surface temperature increases by $1-1.5 \mathrm{~K}$. Recent studies (Bakker et al., 2016; IPCC, 2013) suggest that the Atlantic Meridional Overturning Circulation (AMOC) could weaken in the 21 st century, resulting in a temperature reduction in the North Atlantic. Our simulations reproduce this characteristic cooling of $1 \mathrm{~K}$ in the northern Atlantic that could be caused by a weakening of the AMOC in the 21 st century.

A pronounced global warming would persist even if a strong irradiance drop, scenario SD, occurred in the near future (Fig. 4b). In this scenario, the model suggests a reduction in the warming in northern high latitudes, i.e. the damping of the polar amplification. The surface temperature increase is also damped over continental Africa, Asia and North America, but amplified around Antarctica. The sea surface temperature, although still increasing, shows a smaller warming compared to REF. A study by Menary and Scaife (2014) suggests that the low solar irradiance might cause a strengthening of the AMOC through stratosphere-troposphere coupling. Our results confirm the disappearance of the cooling in the northern Atlantic, likely caused by a recovering AMOC in the grand solar minimum (Muthers et al., 2016). However, this phenomenon needs to be investigated in more detail as it might have an impact on global climate, and especially on the European climate (Jackson et al., 2015).

The surface temperature continues to rise in the 22nd century (Fig. $4 \mathrm{c}$ and d) in both the REF and SD scenarios. REF shows that the further increase is located mostly on the continents, but also in the Pacific, Kamchatka, Alaska and Greenland. The warming patterns in the 22nd century show similar locations of maxima to those at the end of the 21 st, but with a smaller magnitude. The warming during the 22 nd century is less pronounced than in the 21 st century, especially in the $\mathrm{SD}$ case. The maximum warming of $1 \mathrm{~K}$ is located in the high latitudes.

The reduction of the annual mean surface temperatures due to the reduced solar activity at the end of the 21 st century is pronounced in the Arctic, and generally continental areas show lower surface temperature reductions, except for Australia and Europe, as shown in Fig. 5a for the strong reduction (SD) scenario. The sea surface temperatures decrease by up to $0.5 \mathrm{~K}$. The weaker WD scenario also shows a reduced warming, but to a smaller extent (Fig. 5b). The cooling is most prominent in Russia and North America, and is around $1 \mathrm{~K}$. The temperature decrease over sea is confined to the Indian Ocean and does not exceed $0.5 \mathrm{~K}$. In both scenarios assuming a solar anomaly, a temperature increase of up to $1 \mathrm{~K}$ in SD and $0.75 \mathrm{~K}$ in $\mathrm{WD}$, is predicted over the North Atlantic, likely due to a partial recovery of AMOC (Muthers et al., 2016). In the SD scenario, the largest cooling during boreal winter (DJF) is seen over the Barents Sea and northern Asia (Fig. 5c and d). Similar cooling also appears in the WD case. The warming in the North Atlantic and in Greenland is present in boreal winter as well as in the annual mean. Ineson et al. (2015) showed wintertime cooling in northern Eurasia and eastern North America with minima of $-1.5 \mathrm{~K}$ in the 2050-2099 period. Our simulations show a similar but more pronounced pattern for the same period (not shown), possibly due to our applied drop in UV forcing being stronger than the one used by Ineson et al. (2015). Similarly, Chiodo et al. (2016) reported significant cooling in their model simulations in boreal winter in continental Asia and the Bering Sea, with peaks of $-1.2 \mathrm{~K}$ for 2005-2065. In their results, this cooling is accompanied by a warming in North America and off the coast of Japan. Our results for WD suggest a slight 
warming on the east coast of North America and Europe, albeit not a statistically significant warming (not shown).

\subsection{Brewer-Dobson circulation (BDC)}

The transformed Eulerian mean vertical residual velocity ( $w^{*}$; Hardiman et al., 2010) can be used as a measure of intensity of the Brewer-Dobson circulation. Figure 6 shows annual mean $w^{*}$ slightly above tropopause $(70 \mathrm{hPa})$ averaged over $20^{\circ} \mathrm{N}-20^{\circ} \mathrm{S}$, since its maximum is around $15-20^{\circ}$ in both hemispheres (SPARC, 2010). To reduce variability, the curves are smoothed with a Savitzky and Golay (1964) filter.

The BDC accelerates in all experiments. From 1960 throughout the 21 st century, the increase is $2-3 \%$ per decade, which agrees with the SPARC multi-model mean (SPARC, 2010) and the study of Butchart et al. (2006). The intensification is most evident in the first half of the 21st century, when the rate of increase in GHG concentrations is highest (van Vuuren et al., 2011a, Fig. 9). The second half of the 21st century and the 22nd century show a continued acceleration of the BDC at a reduced rate, although it is still statistically significant (at $95 \%$ confidence level using the Mann-Kendall significance test). The intensification is highest in the REF simulation and lower in WD and SD scenarios. However, in WDR and SDR scenarios, after the recovery of solar activity, the BDC quickly adjusts to match the REF scenario at the end of the 22nd century.

\subsection{NO Nesponse $_{x}$}

According to the imposed RCP4.5 scenario, surface emissions of $\mathrm{NO}_{x}$ are projected to decrease and concentrations of $\mathrm{N}_{2} \mathrm{O}$ will increase during the 21 st century. Decreasing $\mathrm{NO}_{x}$ emissions in the troposphere lead to lower $\mathrm{NO}_{x}$ concentrations in REF by up to $80 \%$ by the end of the 21 st century throughout the northern and of up to $40 \%$ throughout the southern troposphere (Fig. 7a). In contrast, increasing $\mathrm{N}_{2} \mathrm{O}$ concentrations lead to increasing $\mathrm{NO}_{x}$ levels in the upper stratosphere due to $\mathrm{N}_{2} \mathrm{O}$ conversion to reactive nitrogen oxides through the reaction with $\mathrm{O}\left({ }^{1} \mathrm{D}\right)$ (Brasseur and Solomon, 2005). By the end of the 21 st century stratospheric $\mathrm{NO}_{x}$ is projected to increase by about $10 \%$. The $\mathrm{NO}_{x}$ decrease by $20 \%$ in the tropical upper troposphere most likely comes from decreasing tropospheric $\mathrm{NO}_{x}$, and therefore there is less $\mathrm{NO}_{x}$ transport from the troposphere into the stratosphere.

Figure $7 \mathrm{~b}$ shows the simulated future change in $\mathrm{NO}_{x}$ volume mixing ratio changes for the SD scenario. The different solar forcing leaves $\mathrm{NO}_{x}$ levels unchanged in the troposphere, where $\mathrm{NO}_{x}$ is dominated by anthropogenic influence. In the stratosphere, however, the effect of the solar irradiance decrease is clearly visible. Reduced NO photolysis limits $\mathrm{NO}_{x}$ removal in the stratosphere via the reaction $\mathrm{N}+$ $\mathrm{NO} \rightarrow \mathrm{N}_{2}+\mathrm{O}$, leading to a more pronounced stratospheric $\mathrm{NO}_{x}$ increase under SD than under REF conditions. Furthermore, the GCR intensity is stronger during grand solar min- ima, leading to enhanced $\mathrm{NO}_{x}$ production in the lower polar stratosphere. This effect, together with faster transport to the polar regions via the $\mathrm{BDC}$, yields around $50 \%$ more $\mathrm{NO}_{x}$ in the Southern Hemisphere and $20 \%$ in the Northern Hemisphere. During the grand solar minimum, the precipitation of LEE is decreased, leading to $60 \%$ reduced production of $\mathrm{NO}_{x}$ in the polar mesosphere.

At the end of the 21st century, the lower photolysis rates in SD relative to REF would yield around $10 \%$ more stratospheric $\mathrm{NO}_{x}$ (Fig. 7c). In contrast, the WD scenario would only lead to a $5 \%$ more stratospheric $\mathrm{NO}_{x}$, i.e. about half the effect of SD (Fig. 7d). As the applied LEE forcing in the model is the same for WD and SD, there is a similar reduction of $\mathrm{NO}_{x}$ of around $80 \%$ in the polar mesosphere.

\subsection{Ozone response}

The Montreal Protocol ODS concentrations are projected to further decrease in future, which is expected to lead to a recovery of stratospheric ozone, mainly in the polar lower stratosphere and globally in the upper stratosphere (Fig. 8a). The decrease in concentrations of chlorine species strongly affects polar lower stratospheric ozone (exceeding $+30 \%$ ), mainly due to a deceleration of heterogeneous chlorine chemistry in the polar winter stratosphere, which is also responsible for the Antarctic "ozone hole" (Solomon et al., 1986). The increase in the upper stratosphere of $15-20 \%$ is a result of reduced intensity of the ozone destruction cycles. In particular in the tropical stratosphere, the increase in ozone is also due to the GHG-induced cooling, which slows the catalytic ozone destruction cycles as well as the reaction $\mathrm{O}+$ $\mathrm{O}_{3} \rightarrow 2 \mathrm{O}_{2}$. In the mesosphere the reaction $\mathrm{O}+\mathrm{O}_{2}+\mathrm{M}$ $\rightarrow \mathrm{O}_{3}+\mathrm{M}$ also becomes important as its reaction rate coefficient increases with cooling (Jonsson et al., 2004), leading to an ozone increase of around $5 \%$. Conversely, the future decline of $\mathrm{NO}_{x}$ surface emissions will result in less tropospheric ozone with a maximum in the Northern Hemisphere of up to $20 \%$.

Besides chemical processes, which depend on ODS concentrations and on temperature, the circulation changes expected to result from GHG-induced radiative changes are also important for ozone. The acceleration of the BDC causes faster transport of ozone from the tropics to high latitudes, causing an ozone decrease in the tropical lower stratosphere exceeding $10 \%$ around $100 \mathrm{hPa}$ (Fig. 8a). The continued acceleration of the BDC during the 22nd century leads to a further reduction of tropical ozone by 5\% (years 2190-2199 relative to 2090-2099, not shown) and an increase in polar regions of $5 \%$.

The strong solar minimum scenario SD shows a similar ozone pattern (Fig. 8b). The increase in ozone in the lower polar stratosphere is the same as in REF, as the impact of ODSs does not seem to depend much on the solar activity. However, in the upper stratosphere the ozone increase is smaller than in the reference case, as its production is sup- 

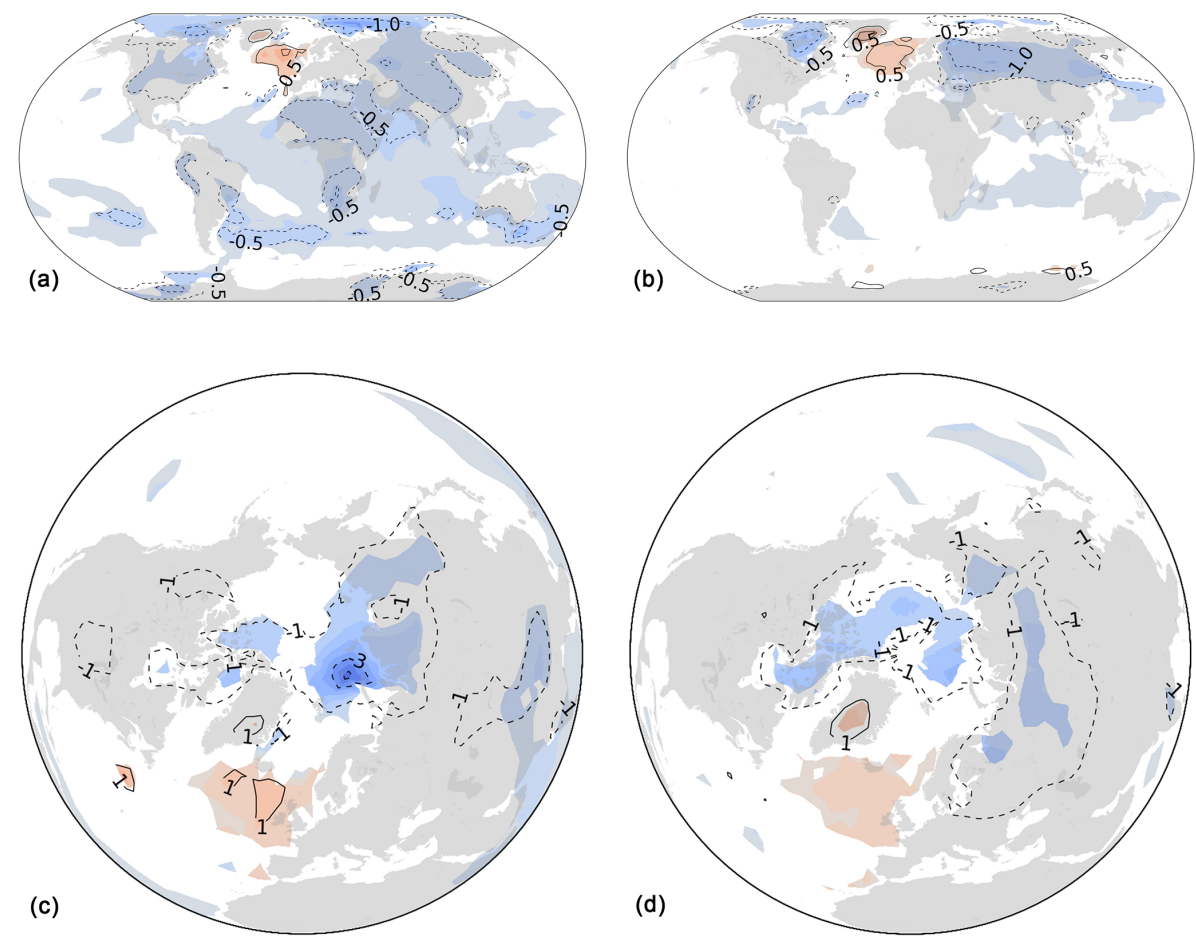

Figure 5. Global projections of spatial distributions of annual mean surface temperature differences in K of ensemble means of SD minus REF (a) and WD minus REF (b) in the late 21st century (2090-2099). Polar projections of boreal winter (DJF) mean surface temperature differences in K of SD minus REF (c) and WD minus REF (d) in the late 21st century (2090-2099). Coloured regions are significant at the $95 \%$ confidence level (calculated using a Student $t$ test). Colour intervals are $0.5 \mathrm{~K}$ in (a) and (b) and $2 \mathrm{~K}$ in (c) and (d).

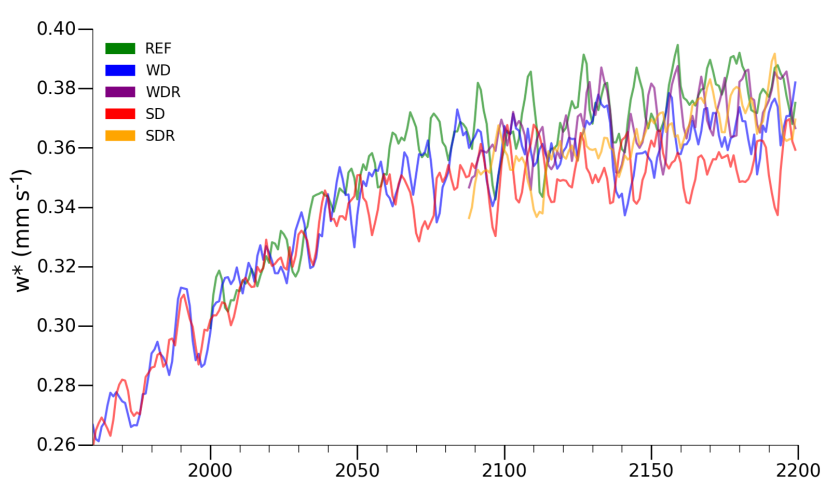

Figure 6. Annual mean residual vertical velocities $\left(w^{*}\right)$ of ensemble means at $70 \mathrm{hPa}$ averaged over $20^{\circ} \mathrm{N}-20^{\circ} \mathrm{S}$ latitudes and smoothed with Savitzky-Golay filter. Weak drop (WD) in blue, weak drop with recovery (WDR) in purple, strong drop (SD) in red and strong drop with recovery (SDR) in orange.

pressed by the decreased UV input. Regardless, decreasing ODS concentrations dominate over a decrease in the solar activity, and therefore stratospheric ozone mixing ratios increase. The ozone decrease in the troposphere and in the tropical stratosphere is very similar to in REF, as it is a result of anthropogenic activities. The most pronounced future differences between ozone in the SD scenario and REF occur in the mesosphere. Reduced photolysis of water vapour results in future decreases in $\mathrm{HO}_{x}$ of $40 \%$ in the mesosphere (not shown), which contribute to the ozone increase at these altitudes. Together with the $\mathrm{NO}_{x}$ decline due to the LEE weakening in the grand solar minimum and the GHG-induced cooling, it leads to an increase in ozone in the mesosphere of up to $35 \%$.

The comparison between SD and REF at the end of the 21 st century is depicted in Fig. 8c. Due to the weaker solar UV irradiance in the grand solar minimum, stratospheric ozone is reduced by up to $8 \%$ in nearly the entire stratosphere in SD compared to the REF scenario. Less mesospheric $\mathrm{NO}_{x}$ and $\mathrm{HO}_{x}$, and colder temperature in the grand solar minimum impacts ozone at these altitudes, leading to an increase of up to $30 \%$. The results are similar in the case of WD, consistent with the smaller (by approximately a factor of 2) UV forcing drop (Fig. 8d).

Figure 9a shows the future increase in the annual mean total ozone column (TOC) over the middle to high latitudes in REF, which is attributed to reduced emissions of ODSs and an enhanced BDC in the warmer climate (Zubov et al., 2013). This future increase reaches 40 (60) Dobson units (DU) in the Northern (Southern) Hemisphere, which corresponds to about $10-20 \%$ of TOC increase. Acceleration of the BDC is expected to transport more ozone from the tropics to midlatitudes fostering extra-tropical ozone recovery, but delay- 


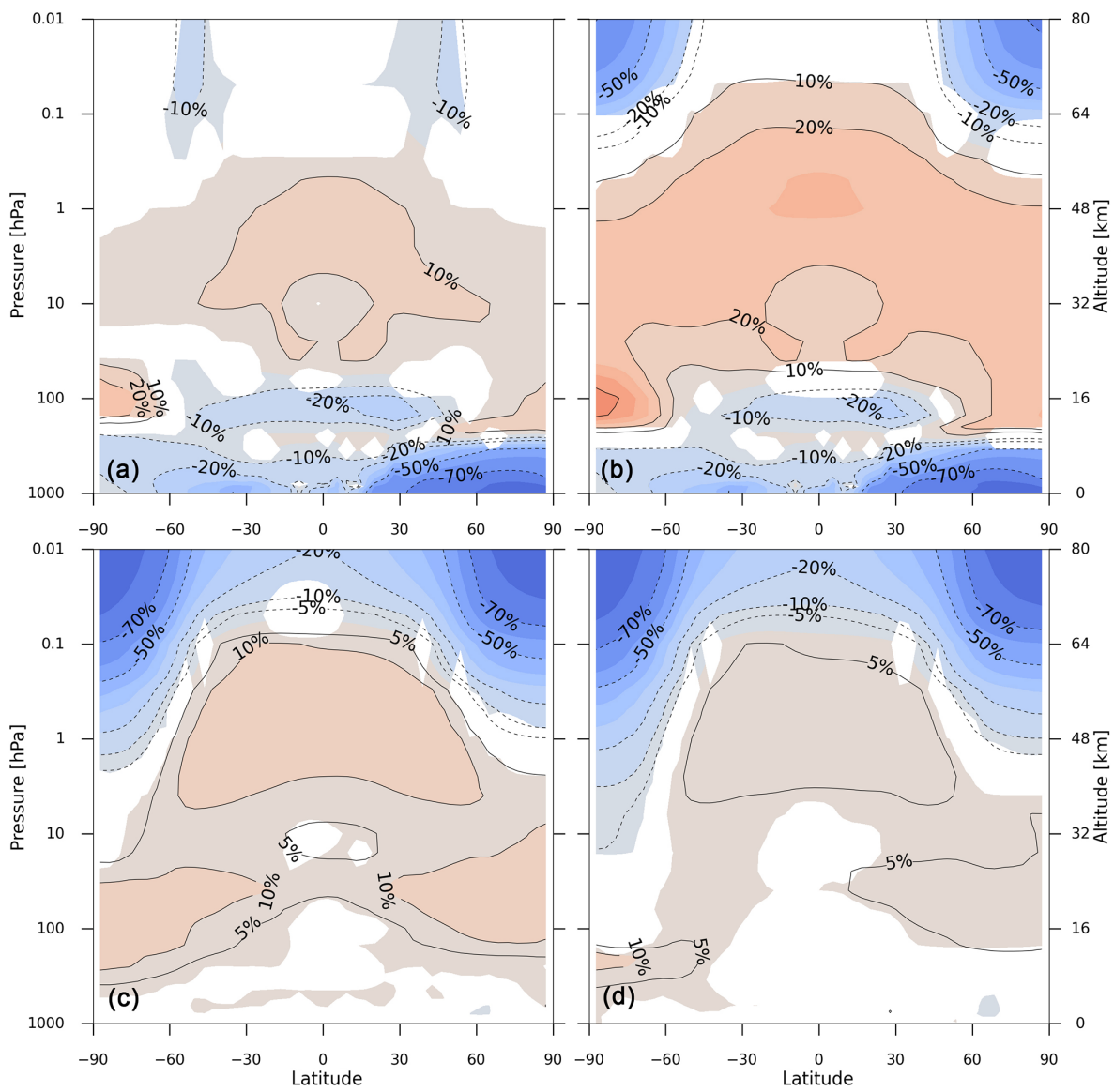

Figure 7. Annual zonal mean $\mathrm{NO}_{x}$ difference in percentage of ensemble means of future (2090-2099) minus near present (2000-2009) for REF (a) and SD (b), and the difference SD - REF (c) and WD - REF (d) under future conditions (2090-2099). Coloured regions are significant at the $95 \%$ confidence level (calculated using a Student $t$ test). Colour interval is $10 \%$.

ing ozone recovery in the tropics (Austin and Wilson, 2006; Shepherd, 2008; Waugh, 2009). Because of this effect, future tropical ozone levels show even further decline at the end of the 21 st century compared to near-present values. The slowing of photochemical ozone loss reactions caused by the cooling in the stratosphere (Barnett et al., 1975; Jonsson et al., 2004) contributes to a smaller degree to the overall TOC evolution (Zubov et al., 2013). Li et al. (2009) showed that the BDC acceleration plays a crucial role in future ozone recovery and spatial distribution. They found recovery of extratropical ozone in year 2060 to 1975-1984 levels, but the tropical TOC did not recover. A study performed by Shepherd (2008) also showed this so-called "super-recovery" of extratropical ozone and "sub-recovery" of tropical ozone by the end of the 21 st century with respect to 1960 values.

Figure 9b illustrates future TOC changes for the SD scenario. A future reduction in solar activity changes the situation dramatically. Weaker solar UV reduces oxygen photolysis, leading to a lower ozone production rate and pronounced TOC depletion in the entire tropical area by around 15-20 DU ( $\widehat{=} 5-6 \%)$. However, a cooler ocean surface due to less solar activity (see Fig. 5a) slightly reduces the BDC relative to REF (see Fig. 6). These two processes cancel out about $30-50 \%$ of the TOC increase in the Northern Hemisphere obtained for REF. Over the Southern Hemisphere the TOC changes are dominated by the reduction in ODSs (Zubov et al., 2013), and therefore the implications of the potential solar minimum are not as dramatic.

The effect of a decrease in the solar activity on the TOC is illustrated in Fig. 10a and b. Both of the grand solar minimum scenarios predict a reduction in TOC, which would be stronger in the SD than in the WD scenario. An ozone reduction of around 10DU in the tropics in SD and 5DU in WD is mostly a result of reduced production, and to a lesser degree because of a very small difference in BDC between the experiments. The most affected areas are mid-latitudes, with a maximum around $20 \mathrm{DU}$ in the SD case (up to $4 \%$ ). Since the polar vortex prevents mixing of ozone-rich air with polar air, ozone-rich air accumulates in the mid-latitudes. We found that a drop in solar activity decelerates polar vortices in both hemispheres (not shown) and, due to the weaker polar vortex, more ozone is able to reach polar areas. Also, during 


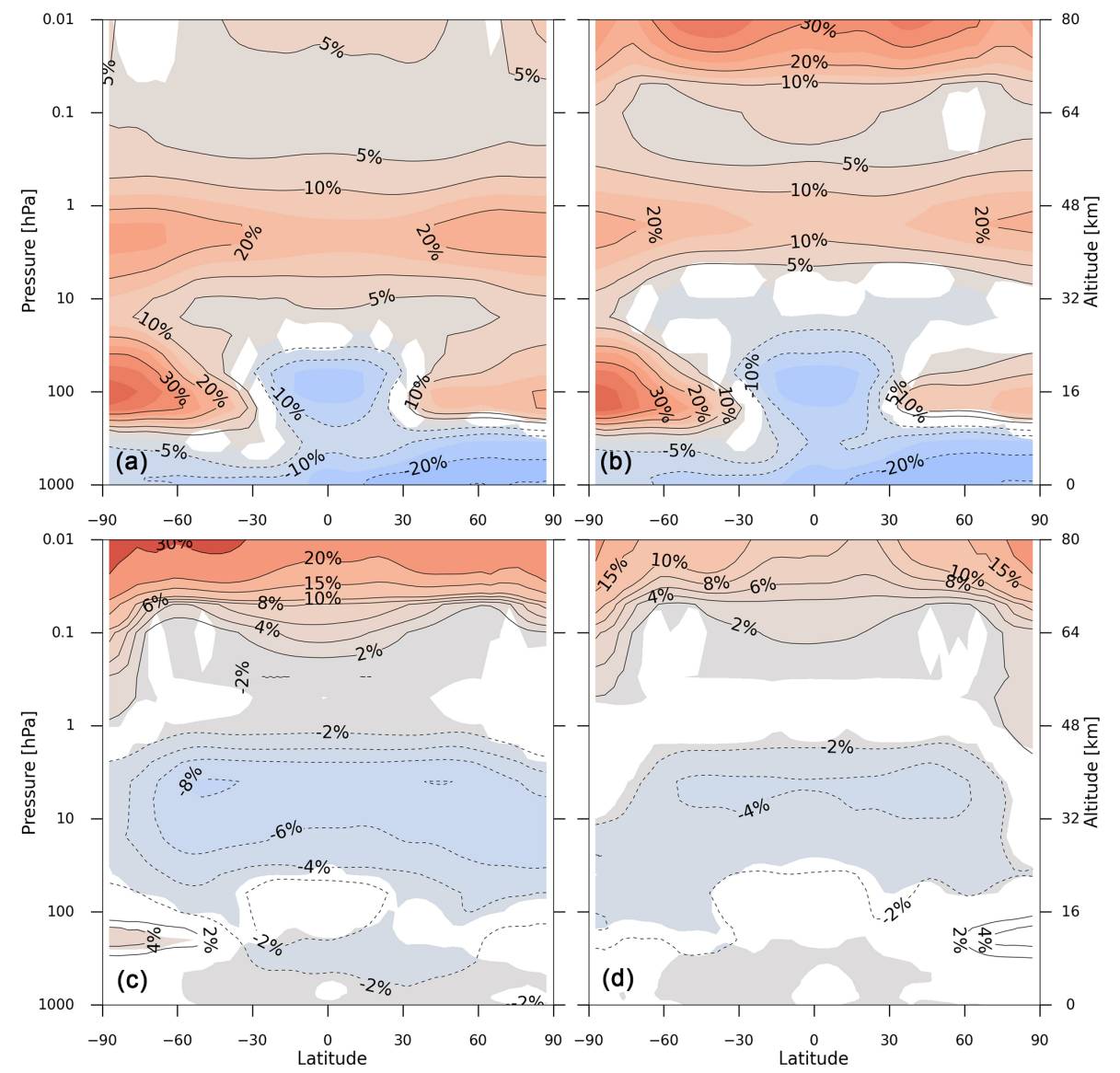

Figure 8. Annual zonal mean ozone difference of ensemble means of future (2090-2099) minus near present (2000-2009) for REF (a) and SD (b), and difference of SD minus REF (c) and WD minus REF (d) for the late 21st century (2090-2099). Coloured regions are significant at the $95 \%$ confidence level (calculated using a Student $t$ test). Colour interval is $5 \%$ in (a) and (b) and $2 \%$ in (c) and (d).
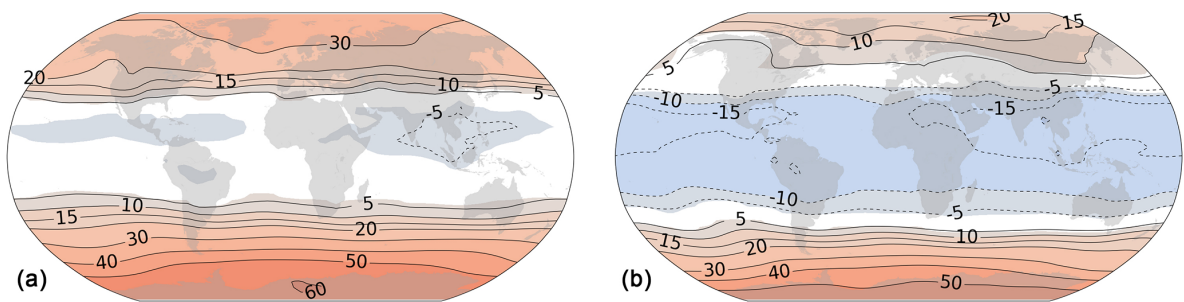

Figure 9. Spatial distribution of total column ozone difference in Dobson units of ensemble means of future (2090-2099) minus near-present (2000-2009) conditions for REF (a) and SD (b). Coloured regions are significant at the $95 \%$ confidence level (calculated using a Student $t$ test). Colour interval is 10 Dobson units.

the grand solar minimum, less ozone is produced in the tropical lower stratosphere. These two factors lead to less accumulation of the ozone-rich air in the mid-latitudes, creating a TOC minimum.

The amount of UV radiation that reaches the surface depends on incoming UV as well as on ozone layer thickness. Although the solar UV input is reduced in the grand solar minimum, we showed that the ozone layer is thinning in the tropical areas. The increase in tropospheric $\mathrm{O}\left({ }^{1} \mathrm{D}\right)$ in the grand solar minimum (not shown) suggests that ozone photolysis by UV $(\lambda<320 \mathrm{~nm})$ is enhanced through the reaction $\mathrm{O}_{3}+h v \rightarrow \mathrm{O}_{2}+\mathrm{O}\left({ }^{1} \mathrm{D}\right)$ (Brasseur and Solomon, 2005). The increase in UV radiation at ground level can have potential positive and negative effects on human health (Reichrath, 2006). UV radiation is important for the production of vitamin D and therefore for human health (Hart et al., 2011), but can also cause skin cancer (Armstrong and Kricker, 2001). Furthermore, UV radiation was shown to be 

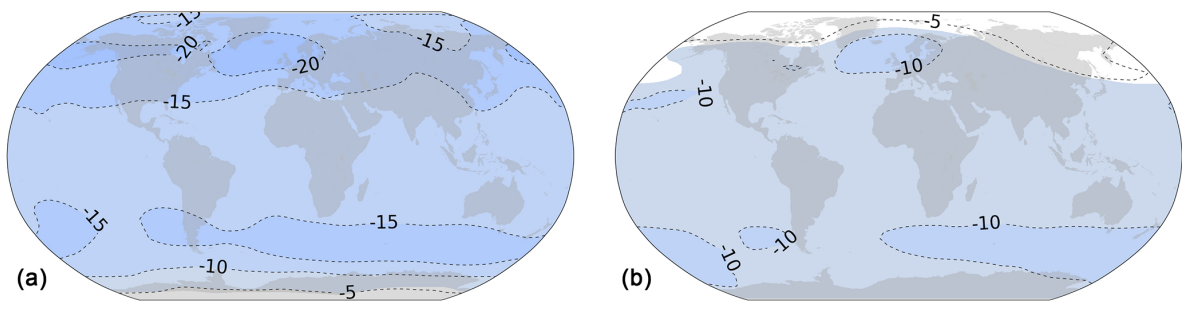

Figure 10. Spatial distribution of total column ozone difference in Dobson units of ensemble means of SD minus REF (a) and WD minus REF (b) for the late 21st century (2090-2099). Coloured regions are significant at the $95 \%$ confidence level (calculated using a Student $t$ test). Colour interval is 5 Dobson units.

harmful to plants as well, damaging DNA, proteins, lipids and membranes (Hollosy, 2002).

A future grand solar minimum could delay the recovery of the ozone layer by several years (Anet et al., 2013). In Fig. 11 we show the annual global mean TOC evolution until the end of the 22nd century. The first decline in total ozone in the 1960-1990 period is caused by the emission of ODSs before the Montreal Protocol came into force. In the beginning of the 21st century, with the Montreal Protocol being effective, total ozone is increasing in all three solar scenarios. In the second half of the century, after a substantial reduction of reactive-halogen-containing species, solar activity turns into the dominant driver of ozone changes. In the reference scenario (REF), the total global ozone recovers to the 1960-1980 values and even exceeds them. However, neither the weak nor the strong solar minimum scenario (WD and SD) show a recovery within the simulated period. If the grand solar minimum persists during the 22 nd century, as the stratospheric temperatures and solar UV irradiance stay unchanged, so does the global mean of TOC. However, as the BDC continues to accelerate, it will continue to redistribute ozone from the tropics to the polar regions, which may lead to the absence of strong trends in the global mean value. When the grand minimum recovers, TOC recovers to REF values readily.

\section{Conclusions and Outlook}

In this paper we investigated the influence of a potential future grand solar minimum on atmospheric chemistry and climate. Such an event, should it occur with the extreme intensity assumed here, could temporarily partly counteract the anthropogenic climate change caused by ongoing emissions of greenhouse gases that follow the RCP4.5 scenario. However, it would still be by far too weak to fully compensate for it. Even if the grand solar minimum were fully developed by the year 2090 and then lasted until the end of the 22nd century, global mean surface temperatures would continue to rise. A solar minimum, assuming a very large drop in solar irradiance (SD scenario) is predicted to compensate for about $15 \%$ of GHG-induced warming by 2100 . However,

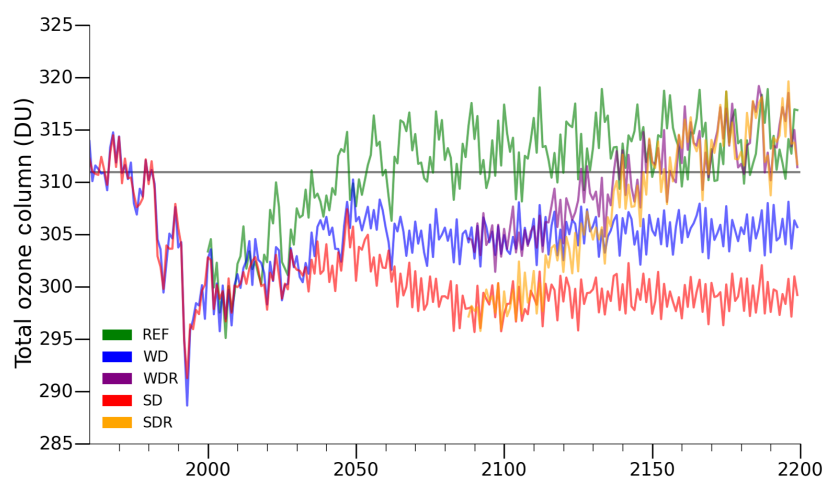

Figure 11. Annual global mean total column ozone in Dobson units of ensemble mean values for the 1960 to 2199 period. The horizontal grey line presents the $1960-1980$ period mean value.

this fraction could increase to about $25 \%$ during the 22 nd century, suggesting that the Earth system is still equilibrating to the increased GHG concentrations (which stay approximately constant during the 22nd century within RCP4.5). For the lowest GHG concentration scenario, RCP2.6, the IPCC (2013) multi-model mean projects global warming at the end of the 21 st century of $1 \pm 0.4^{\circ} \mathrm{C}$. Our results show that even in this case, the extreme drop in solar activity would only reduce the projected increase in surface temperature by around $20-50 \%$. As expected, for the higher RCPs, 6.0 and 8.5, the grand solar minimum would result in only very minor reduction of the warming. This let us conclude that a strong drop in solar forcing would help the global community to reach the Paris Agreement goal for RCP2.6 and increase the chance of reaching it for RCP4.5. Nevertheless, the multi-model mean of RCP4.5 (IPCC, 2013) would still be above the $2{ }^{\circ} \mathrm{C}$ threshold, and other problems like ocean acidification due to higher atmospheric $\mathrm{CO}_{2}$ concentrations would still lead to significant damages to global ecosystems.

Areas with the highest partial compensation of global warming are located in high northern latitudes, especially in the winter season. Our results suggest that a grand solar minimum could lead to a recovery of AMOC, which might cancel out the cooling in the North Atlantic in the 21st century (Muthers et al., 2016). More research should be done to 
address the uncertainty of the solar influence on the AMOC response.

A cooling caused by the weaker solar activity occurs throughout the middle atmosphere, with a prominent maximum in the mesosphere. Our results indicate an increase in stratospheric $\mathrm{NO}_{x}$ via decreased UV radiation and a decrease in mesospheric $\mathrm{NO}_{x}$ as the EPP becomes weaker in a grand solar minimum. Water vapour photolysis is also decreased during the grand solar minimum, leading to reduced $\mathrm{HO}_{x}$ concentrations. The declines of $\mathrm{NO}_{x}$ and $\mathrm{HO}_{x}$, together with the reduced UV heating, result in an ozone increase in the mesosphere. In the stratosphere, although the ozone production is reduced here, as well due to the decrease in solar UV, the reduction of ODSs causes an increase in ozone.

While this study includes the effect of energetic particle precipitation for high and low energetic particles (such as GCRs and LEEs, respectively), future work should also concentrate on energetic electrons of higher energies (Matthes et al., 2016) and thus evaluate more precisely their effect on future climate. The flux of energetic electrons is dependent on solar activity (e.g. Sinnhuber et al., 2012) and in the grand solar minimum its intensity is diminished. By including these particles in climate models, we can expect an amplification of our results in the grand solar minimum - less $\mathrm{NO}_{x}$ produced and more stratospheric ozone preserved in polar regions, followed by further changes in dynamics and temperature (Arsenovic et al., 2016).

While the future grand solar minimum reduces surface temperature to some degree, it poses another problem: thinning of the tropical ozone layer. The acceleration of the BDC caused by the warming of tropospheric climate due to the GHGs transports the freshly formed ozone more quickly away from the tropical into extra-tropical areas and give catalytic chemical cycles less time to deplete ozone. As a consequence, the extra-tropical areas will reach a "super-recovery" of ozone, while the tropical areas display negative anomalies. Even if the grand solar minimum does not occur, the total ozone in the tropics will be reduced compared to present values. Since the probability of the grand solar minimum happening in the 21st century is rather high (Steinhilber and Beer, 2013), this will compromise the ozone recovery even after a low level of active halogens will be reached. The tropical regions would suffer a loss of up to $6 \%$ of the column ozone compared to present values, and tropical ozone would not reach the recovery to the pre-ozone hole (1960-1980) levels. Therefore, all efforts to reduce GHG emissions and the fulfilment of the Paris Agreement are absolutely crucial. The possibility of failing the Paris climate agreement also brings the risk of thinning the tropical ozone layer.

In the strong and weak solar scenarios, SD and WD, the acceleration of atmospheric dynamics persists throughout the 22nd century, leading to an ozone redistribution from the tropics to the poles, but the global total ozone would stay at similar levels to at the end of the 21 st century. In the SDR and WDR scenarios, when the solar minimum recovers during the 22nd century, global total ozone would increase rapidly and recover (or super-recover).

Stratospheric ozone plays a key role for terrestrial life as it absorbs UV radiation. Although UV radiation is decreased during the grand solar minimum, the fact that the ozone layer is thinning allows more UV to reach the ground. The increase in UV radiation at the ground level in the grand solar minimum could have implications on the terrestrial ecosystem and needs to be investigated in future studies.

Data availability. Due to the size limitation, SOCOL3-MPIOM model code and used boundary conditions are only available upon request. The model output analysed in this study can be downloaded from https://data.mendeley.com/datasets/hhrgx238sn (Arsenovic, 2018).

Competing interests. The authors declare that they have no conflict of interest.

Acknowledgements. This work has been supported by the Swiss National Science Foundation under grant CRSII2-147659 (FUPSOL II) and it is a part of ROSMIC WG1 activity within the SCOSTEP VarSITI program. We would like to sincerely thank the co-editor, Christopher Hoyle from PSI, Switzerland, and two anonymous reviewers whose comments significantly improved the paper.

Edited by: Christopher Hoyle

Reviewed by: two anonymous referees

\section{References}

Abreu, J. A., Beer, J., and Ferriz-mas, A.: Past and Future Solar Activity from Cosmogenic Radionuclides, SOHO 23 Underst. a Peculiar Sol. Minim., 428, 287-295, 2010.

Anet, J. G., Rozanov, E. V., Muthers, S., Peter, T., Brönnimann, S., Arfeuille, F., Beer, J., Shapiro, A. I., Raible, C. C., Steinhilber, F., and Schmutz, W. K.: Impact of a potential 21 st century "grand solar minimum" on surface temperatures and stratospheric ozone, Geophys. Res. Lett., 40, 4420-4425, https://doi.org/10.1002/grl.50806, 2013.

Anet, J. G., Muthers, S., Rozanov, E. V., Raible, C. C., Stenke, A., Shapiro, A. I., Brönnimann, S., Arfeuille, F., Brugnara, Y., Beer, J., Steinhilber, F., Schmutz, W., and Peter, T.: Impact of solar versus volcanic activity variations on tropospheric temperatures and precipitation during the Dalton Minimum, Clim. Past, 10, 921-938, https://doi.org/10.5194/cp-10-921-2014, 2014.

Armstrong, B. K. and Kricker, A.: The epidemiology of UV induced skin cancer, J. Photochem. Photobiol. B Biol., 63, 8-18, https://doi.org/10.1016/S1011-1344(01)00198-1, 2001.

Arsenovic, P.: CCM SOCOL3-MPOIM model output, available at: https://data.mendeley.com/datasets/hhrgx238sn, last access: 8 March 2018. 
Arsenovic, P., Rozanov, E., Stenke, A., Funke, B., Wissing, J. M., Mursula, K., Tummon, F., and Peter, T.: The influence of Middle Range Energy Electrons on atmospheric chemistry and regional climate, J. Atmos. Sol-Terr. Phys., 149, 180-190, https://doi.org/10.1016/j.jastp.2016.04.008, 2016.

Austin, J. and Wilson, R. J.: Ensemble simulations of the decline and recovery of stratospheric ozone, J. Geophys. Res.-Atmos., 111, 1-16, https://doi.org/10.1029/2005JD006907, 2006.

Bakker, P., Schmittner, A., Lenaerts, J. T. M., Abe-Ouchi, A., Bi, D., Broeke, M. R., Chan, W.-L., Hu, A., Beadling, R. L., Marsland, S. J., Mernild, S. H., Saenko, O. A., Swingedouw, D., Sullivan, A., and Yin, J.: Fate of the Atlantic Meridional Overturning Circulation - Strong decline under continued warming and Greenland melting, Geophys. Res. Lett., 43, 12252-12260, https://doi.org/10.1002/2016GL070457, 2016.

Barnett, J. J., Houghton, J. T., and Pyle, J. A.: The temperature dependence of the ozone concentration near the stratopause, Q. J. Roy. Meteor. Soc., 101, 245-257, https://doi.org/10.1002/qj.49710142808, 1975.

Bazilevskaya, G. A., Usoskin, I. G., Flückiger, E. O., Harrison, R. G., Desorgher, L., Bütikofer, R., Krainev, M. B., Makhmutov, V. S., Stozhkov, Y. I., Svirzhevskaya, A. K., Svirzhevsky, N. S., and Kovaltsov, G. A.: Cosmic ray induced ion production in the atmosphere, Space Sci. Rev., 137, 149-173, https://doi.org/10.1007/s11214-008-9339-y, 2008.

Brasseur, G. and Solomon, S.: Aeronomy of the Middle Atmosphere: Chemistry and Physics of the Stratosphere and Mesosphere, third ed. Springer, Dordrecht, the Netherlands, 2005.

Brugnara, Y., Brönnimann, S., Luterbacher, J., and Rozanov, E.: Influence of the sunspot cycle on the Northern Hemisphere wintertime circulation from long upper-air data sets, Atmos. Chem. Phys., 13, 6275-6288, https://doi.org/10.5194/acp-136275-2013, 2013.

Butchart, N., Scaife, A. A., Bourqui, M., de Grandpré, J., Hare, S. H. E., Kettleborough, J., Langematz, U., Manzini, E., Sassi, F., Shibata, K., Shindell, D., and Sigmond, M.: Simulations of anthropogenic change in the strength of the Brewer-Dobson circulation, Clim. Dynam., 27, 727-741, https://doi.org/10.1007/s00382-006-0162-4, 2006.

Calisto, M., Usoskin, I., Rozanov, E., and Peter, T.: Influence of Galactic Cosmic Rays on atmospheric composition and dynamics, Atmos. Chem. Phys., 11, 4547-4556, https://doi.org/10.5194/acp-11-4547-2011, 2011.

Chiodo, G., García-Herrera, R., Calvo, N., Vaquero, J. M., Añel, J. A., Barriopedro, D., and Matthes, K.: The impact of a future solar minimum on climate change projections in the Northern Hemisphere, Environ. Res. Lett., 11, 34015, https://doi.org/10.1088/1748-9326/11/3/034015, 2016.

Dorman, L. I.: Cosmic rays in the earth's atmosphere and underground, Dordrecht, Kluwer Academic Publishers, 2004.

Egorova, T., Rozanov, E., Zubov, V., and Karol, I.: Model for investigating ozone trends (MEZON), Izv. Atmos. Ocean. Phy., 39, 277-292, 2003.

Feulner, G.: Are the most recent estimates for Maunder Minimum solar irradiance in agreement with temperature reconstructions?, Geophys. Res. Lett., 38, 1-4, https://doi.org/10.1029/2011GL048529, 2011.
Foukal, P., Ortiz, A., and Schnerr, R.: Dimming of the 17 th Century Sun, Sol. Phys., 733, https://doi.org/10.1088/20418205/733/2/L38, 2011.

Hardiman, S. C., Andrews, D. G., White, A. A., Butchart, N., and Edmond, I.: Using Different Formulations of the Transformed Eulerian Mean Equations and Eliassen-Palm Diagnostics in General Circulation Models, J. Atmos. Sci., 67, 1983-1995, https://doi.org/10.1175/2010JAS3355.1, 2010.

Hart, P. H., Gorman, S., and Finlay-Jones, J. J.: Modulation of the immune system by UV radiation: more than just the effects of vitamin D?, Nat. Rev. Immunol., 11, 584-596, https://doi.org/10.1038/nri3045, 2011.

Hegglin, M. I., Fahey, D. W., McFarland, M., Montzka, S. A., and Nash, E. R.: 20 Questions and Answers About the Ozone Layer: 2014 Update, Scientific Assessment of Ozone Depletion: 2014, 2015.

Hollosy, F.: Effects of ultraviolet radiation on plant cells, Micron, 33, 179-197, https://doi.org/10.1016/S0968-4328(01)00011-7, 2002.

Hoyt, D. V. and Schatten, K. H.: Group Sunspot Numbers: A new solar activity reconstruction, Sol. Phys., 181, 491-512, https://doi.org/10.1023/A:1005007527816, 1998.

Ineson, S., Maycock, A. C., Gray, L. J., Scaife, A. A., Dunstone, N. J., Harder, J. W., Knight, J. R., Lockwood, M., Manners, J. C., and Wood, R. A.: Regional climate impacts of a possible future grand solar minimum, Nat. Commun., 6, 7535, https://doi.org/10.1038/ncomms8535, 2015.

IPCC: Climate Change 2013: The Physical Science Basis. Contribution of Working Group I to the Fifth Assessment Report of the Intergovernmental Panel on Climate Change, edited by: Stocker, T. F., Qin, D., Plattner, G.-K., Tignor, M., Allen, S. K., Boschung, J., Nauels, A., Xia, Y., Bex, V., and Midgley, P. M., Cambridge University Press, Cambridge, United Kingdom and New York, NY, USA, 1535 pp., 2013.

Jackman, C. H., Marsh, D. R., Kinnison, D. E., Mertens, C. J., and Fleming, E. L.: Atmospheric changes caused by galactic cosmic rays over the period 1960-2010, Atmos. Chem. Phys., 16, 58535866, https://doi.org/10.5194/acp-16-5853-2016, 2016.

Jackson, L. C., Kahana, R., Graham, T., Ringer, M. A., Woollings, T., Mecking, J. V., and Wood, R. A.: Global and European climate impacts of a slowdown of the AMOC in a high resolution GCM, Clim. Dyn., 45, 3299-3316, https://doi.org/10.1007/s00382-015-2540-2, 2015.

Jonsson, A. I., de Grandpré, J., Fomichev, V. I., McConnell, J. C., and Beagley, S. R.: Doubled $\mathrm{CO}_{2}$-induced cooling in the middle atmosphere: Photochemical analysis of the ozone radiative feedback, J. Geophys. Res.-Atmos., 109, 1-18, https://doi.org/10.1029/2004JD005093, 2004.

Judge, P. G., Lockwood, G. W., Radick, R. R., Henry, G. W., Shapiro, A. I., Schmutz, W., and Lindsey, C.: Confronting a solar irradiance reconstruction with solar and stellar data, Astron. Astrophys., 544, A88, https://doi.org/10.1051/00046361/201218903, 2012.

Kopp, G.: Magnitudes and timescales of total solar irradiance variability, J. Sp. Weather Sp. Clim., 6, A30, https://doi.org/10.1051/swsc/2016025, 2016.

Li, F., Stolarski, R. S., and Newman, P. A.: Stratospheric ozone in the post-CFC era, Atmos. Chem. Phys., 9, 2207-2213, https://doi.org/10.5194/acp-9-2207-2009, 2009. 
Lockwood, M., Owens, M. J., Barnard, L., Davis, C. J., and Steinhilber, F.: The persistence of solar activity indicators and the descent of the Sun into Maunder Minimum conditions, Geophys. Res. Lett., 38, 1-5, https://doi.org/10.1029/2011GL049811, 2011.

Luterbacher, J., Dietrich, D., Xoplaki, E., Grosjean, M., and Wanner, H.: European Seasonal and Annual Temperature Variability, Trends, and Extremes Since 1500, Science, 303, 1499-1503, https://doi.org/10.1126/science.1093877, 2004.

Manzini, E., Giorgetta, M. A., Esch, M., Kornblueh, L., and Roeckner, E.: The influence of sea surface temperatures on the northern winter stratosphere: Ensemble simulations with the MAECHAM5 model, J. Clim., 19, 3863-3881, https://doi.org/10.1175/JCLI3826.1, 2006.

Matthes, K., Funke, B., Andersson, M. E., Barnard, L., Beer, J., Charbonneau, P., Clilverd, M. A., Dudok de Wit, T., Haberreiter, M., Hendry, A., Jackman, C. H., Kretzschmar, M., Kruschke, T., Kunze, M., Langematz, U., Marsh, D. R., Maycock, A. C., Misios, S., Rodger, C. J., Scaife, A. A., Seppälä, A., Shangguan, M., Sinnhuber, M., Tourpali, K., Usoskin, I., van de Kamp, M., Verronen, P. T., and Versick, S.: Solar forcing for CMIP6 (v3.2), Geosci. Model Dev., 10, 2247-2302, https://doi.org/10.5194/gmd-10-2247-2017, 2016.

Maycock, A. C., Ineson, S., Gray, L. J., Scaife, A. A., Anstey, J. A., Lockwood, M., Butchart, N., Hardiman, S. C., Mitchell, D. M., and Osprey, S. M.: Possible impacts of a future grand solar minimum on climate: Stratospheric and global circulation changes, J. Geophys. Res.-Atmos., 120, 9043-9058, https://doi.org/10.1002/2014JD022022, 2015.

Meehl, G. A., Arblaster, J. M., and Marsh, D. R.: Could a future "grand Solar Minimum" like the Maunder Minimum stop global warming?, Geophys. Res. Lett., 40, 1789-1793, https://doi.org/10.1002/grl.50361, 2013.

Meinshausen, M., Smith, S. J., Calvin, K., Daniel, J. S., Kainuma, M. L. T., Lamarque, J., Matsumoto, K., Montzka, S. A., Raper, S. C. B., Riahi, K., Thomson, A., Velders, G. J. M., and van Vuuren, D. P. P.: The RCP greenhouse gas concentrations and their extensions from 1765 to 2300 , Clim. Change, 109, 213241, https://doi.org/10.1007/s10584-011-0156-z, 2011.

Menary, M. B. and Scaife, A. A.: Naturally forced multidecadal variability of the Atlantic meridional overturning circulation, Clim. Dyn., 42, 1347-1362, https://doi.org/10.1007/s00382-0132028-x, 2014.

Mironova, I. A., Aplin, K. L., Arnold, F., Bazilevskaya, G. A., Harrison, R. G., Krivolutsky, A. A., Nicoll, K. A., Rozanov, E. V., Turunen, E., and Usoskin, I. G.: Energetic Particle Influence on the Earth's Atmosphere, Space Sci. Rev., 194, 1-96, https://doi.org/10.1007/s11214-015-0185-4, 2015.

Mokhov, I. I., Bezverkhnii, V. A., Eliseev, A. V., and Karpenko, A. A.: Model Estimations of Possible Climatic Changes in 21st Century at Different Scenarios of Solar and Volcanic Activities and Anthropogenic Impact, Cosm. Res., 46, 354-357, https://doi.org/10.1134/S0010952508040114, 2008.

Muthers, S., Anet, J. G., Stenke, A., Raible, C. C., Rozanov, E., Brönnimann, S., Peter, T., Arfeuille, F. X., Shapiro, A. I., Beer, J., Steinhilber, F., Brugnara, Y., and Schmutz, W.: The coupled atmosphere-chemistry-ocean model SOCOL-MPIOM, Geosci. Model Dev., 7, 2157-2179, https://doi.org/10.5194/gmd-7-21572014, 2014.
Muthers, S., Raible, C. C., Rozanov, E., and Stocker, T. F.: Response of the AMOC to reduced solar radiation - the modulating role of atmospheric chemistry, Earth Syst. Dynam., 7, 877-892, https://doi.org/10.5194/esd-7-877-2016, 2016.

Newman, P. A. and Rosenfield, J. E.: Stratospheric thermal damping times, Geophys. Res. Lett., 24, 433-436, https://doi.org/10.1017/CBO9781107415324.004, 1997.

Reichrath, J.: The challenge resulting from positive and negative effects of sunlight: How much solar UV exposure is appropriate to balance between risks of vitamin $\mathrm{D}$ deficiency and skin cancer?, Prog. Biophys. Mol. Biol., 92, 9-16, https://doi.org/10.1016/j.pbiomolbio.2006.02.010, 2006.

Roeckner, E.: The atmospheric general circulation model ECHAM5: Model description, Hamburg, 2003.

Roeckner, E., Brokopf, R., Esch, M., Giorgetta, M. A., Hagemann, S., Kornblueh, L., Manzini, E., Schlese, U., and Schulzweida, U.: Sensitivity of simulated climate to horizontal and vertical resolution in the ECHAM5 atmosphere model, J. Clim., 19, 37713791, https://doi.org/10.1175/JCLI3824.1, 2006.

Roth, R. and Joos, F.: A reconstruction of radiocarbon production and total solar irradiance from the Holocene ${ }^{14} \mathrm{C}$ and $\mathrm{CO}_{2}$ records: implications of data and model uncertainties, Clim. Past, 9, 1879-1909, https://doi.org/10.5194/cp-9-1879-2013, 2013.

Rozanov, E., Calisto, M., Egorova, T., Peter, T., and Schmutz, W.: Influence of the Precipitating Energetic Particles on Atmospheric Chemistry and Climate, Surv. Geophys., 33, 483-501, https://doi.org/10.1007/s10712-012-9192-0, 2012.

Rozanov, E. V., Zubov, V. A., Schlesinger, M. E., Yang, F., and Andronova, N. G.: The UIUC three-dimensional stratospheric chemical transport model: Description and evaluation of the simulated source gases and ozone, J. Geophys. Res., 104, 11755, https://doi.org/10.1029/1999JD900138, 1999.

Savitzky, A. and Golay, M. J. E.: Smoothing and Differentiation of Data by Simplified Least Squares Procedures, Anal. Chem., 36, 1627-1639, https://doi.org/10.1021/ac60214a047, 1964.

Schrijver, C. J., Livingston, W. C., Woods, T. N., and Mewaldt, R. A.: The minimal solar activity in 2008-2009 and its implications for long-term climate modeling, Geophys. Res. Lett., 38, 1-6, https://doi.org/10.1029/2011GL046658, 2011.

Serreze, M. C. and Barry, R. G.: Processes and impacts of Arctic amplification: A research synthesis, Glob. Planet. Change, 77, 85-96, https://doi.org/10.1016/j.gloplacha.2011.03.004, 2011.

Shapiro, A. V. I., Schmutz, W., Rozanov, E., Schoell, M., Haberreiter, M., Shapiro, A. V. I., and Nyeki, S.: A new approach to the long-term reconstruction of the solar irradiance leads to large historical solar forcing, Astron. Astrophys., 529, A67, https://doi.org/10.1051/0004-6361/201016173, 2011.

Shepherd, T. G.: Dynamics, stratospheric ozone, and climate change, Atmos. Ocean, 46, 117-138, https://doi.org/10.3137/ao.460106, 2008.

Sinnhuber, M., Nieder, H., and Wieters, N.: Energetic Particle Precipitation and the Chemistry of the Mesosphere/Lower Thermosphere, Surv. Geophys., 33, 1281-1334, https://doi.org/10.1007/s10712-012-9201-3, 2012.

Solomon, S., Garcia, R. R., Rowland, F. S., and Wuebbles, D. J.: On the depletion of Antarctic ozone, Nature, 321, 755-758, https://doi.org/10.1038/321755a0, 1986.

SPARC: SPARC CCMVal Report on the Evaluation of ChemistryClimate Models, edited by: Eyring, V., Shepherd, T., and Waugh, 
D., SPARC Report No. 5, WCRP-30/2010, WMO/TD - No. 40, available at: www.sparc-climate.org/publications/sparc-reports/ (last access: 7 March 2018), 2010.

Steinhilber, F. and Beer, J.: Prediction of solar activity for the next 500 years, J. Geophys. Res.-Sp. Phys., 118, 1861-1867, https://doi.org/10.1002/jgra.50210, 2013.

Stenke, A., Schraner, M., Rozanov, E., Egorova, T., Luo, B., and Peter, T.: The SOCOL version 3.0 chemistry-climate model: description, evaluation, and implications from an advanced transport algorithm, Geosci. Model Dev., 6, 1407-1427, https://doi.org/10.5194/gmd-6-1407-2013, 2013.

Usoskin, I. G., Kovaltsov, G. A., and Mironova, I. A.: Cosmic ray induced ionization model CRAC:CRII: An extension to the upper atmosphere, J. Geophys. Res.-Atmos., 115, 1-6, https://doi.org/10.1029/2009JD013142, 2010.

van Vuuren, D. P., Edmonds, J., Kainuma, M., Riahi, K., Thomson, A., Hibbard, K., Hurtt, G. C., Kram, T., Krey, V., Lamarque, J. F., Masui, T., Meinshausen, M., Nakicenovic, N., Smith, S. J., and Rose, S. K.: The representative concentration pathways: An overview, Clim. Change, 109, 5-31, https://doi.org/10.1007/s10584-011-0148-z, 2011a. van Vuuren, D., Stehfest, E., den Elzen, M., Kram, T., van Vliet, J., Deetman, S., Isaac, M., Klein Goldewijk, K., Hof, A., Mendoza Beltran, A., Oostenrijk, R., and van Ruijven, B.: RCP 2.6: exploring the possibility to keep global mean temperature increase below $2{ }^{\circ} \mathrm{C}$, Clim. Change, 109, 95-116, https://doi.org/10.1007/s10584-011-0152-3, 2011 b.

Waugh, D.: Atmospheric dynamics: The age of stratospheric air, Nat. Geosci., 2, 14-16, https://doi.org/10.1038/ngeo397, 2009.

World Meteorological Organization (WMO), Scientific Assessment of Ozone Depletion: 2014, World Meteorological Organization, Global Ozone Research and Monitoring Project - Report No. 55, 416 pp., Geneva, Switzerland, 2014.

Zubov, V., Rozanov, E., Egorova, T., Karol, I., and Schmutz, W.: Role of external factors in the evolution of the ozone layer and stratospheric circulation in 21st century, Atmos. Chem. Phys., 13, 4697-4706, https://doi.org/10.5194/acp-13-4697-2013, 2013 